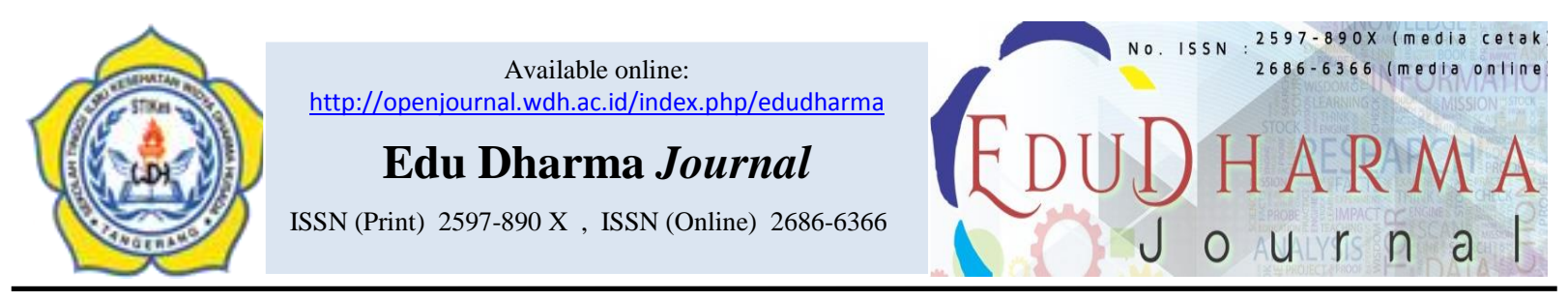

\title{
TOKSISITAS EKSTRAK UMBI SINGKONG (Manihot esculanta Crantz)
}

\author{
Nur Hasanah ${ }^{1^{*}}$, Ihsan Nursobah ${ }^{2}$, Nur Wulan Adi Ismaya ${ }^{3}$, \\ ${ }^{1,2,3}$ STIKes Kharisma Persada, Jalan Pajajaran No.1, Pamulang, Tangerang Selatan 15417, Indonesia
}

\begin{tabular}{|c|c|}
\hline ARTICLE INFORMATION & $A B S T R A C T$ \\
\hline $\begin{array}{l}\text { * Nur Wulan Adi Ismaya } \\
\text { E-mail:nurwulan@masda.ac.id }\end{array}$ & $\begin{array}{l}\text { Cassava bulbs (Manihot esculanta Crantz) is one of the food plants that } \\
\text { grow in Indonesia. Cassava bulbs find Alkaloids, Saponins, Phenolics, } \\
\text { Flavonoids, Triterpenoids, and Glycosides. The purpose of this research is } \\
\text { to know more about cassava extract (Manihot Esculanta Crantz), to know } \\
\text { the appearance of cassava extract (Manihot esculanta Crantz), and to }\end{array}$ \\
\hline $\begin{array}{l}\text { Keywords: (3-5 words or phrase) } \\
\text { Toxicity_1 } \\
\text { Cassava_Tuber Extract (Manihot } \\
\text { esculanta Crantz)_2 } \\
\text { Brine Shrimp Lethality Test (BSLT)_3 }\end{array}$ & $\begin{array}{l}\text { Crantz). The method used in this study is the method of Brine Shrimp } \\
\text { Lethality Test (BSLT). This research used Artemia salina Leach larvae test } \\
\text { animals which were divided into } 9 \text { groups, each group consisted of } 10 \\
\text { tails, with replication } 2 \text { times each group. The concentration of cassava } \\
\text { extract (Manihot esculanta Crantz) is } 0 \text { ppm, } 10 \text { ppm, } 50 \text { ppm, } 100 \text { ppm, } \\
300 \text { ppm, } 500 \text { ppm, } 600 \text { ppm, } 800 \text { ppm, and } 1000 \text { ppm, and extract } \\
\text { partition with Ethanol, n- Heksan, and Ethyl acetate. Observation of dead } \\
\text { larvae was performed } 24 \text { hours after administration of the extract. Based } \\
\text { on the data, LC } C_{50} \text { cassava extract (Manihot esculenta, Crantz) was } \\
\text { determined by probit analysis. The result of probit analysis showed LC } C_{50} \\
\text { Ethanol phase showed value } 1462 \text { ppm, n-Hexane phase showed LC } C_{50} \\
\text { value } 2994 \text { ppm, and phase of Ethyl acetate showed LC } C_{50} \text { value } 3217 \text { ppm. } \\
\text { The results show that cassava tuber extract (Manihot esculenta, Crantz) } \\
\text { did not show toxic potential, this is indicated by the price of LC } C_{50}>1000 \\
\text { ppm. }\end{array}$ \\
\hline
\end{tabular}




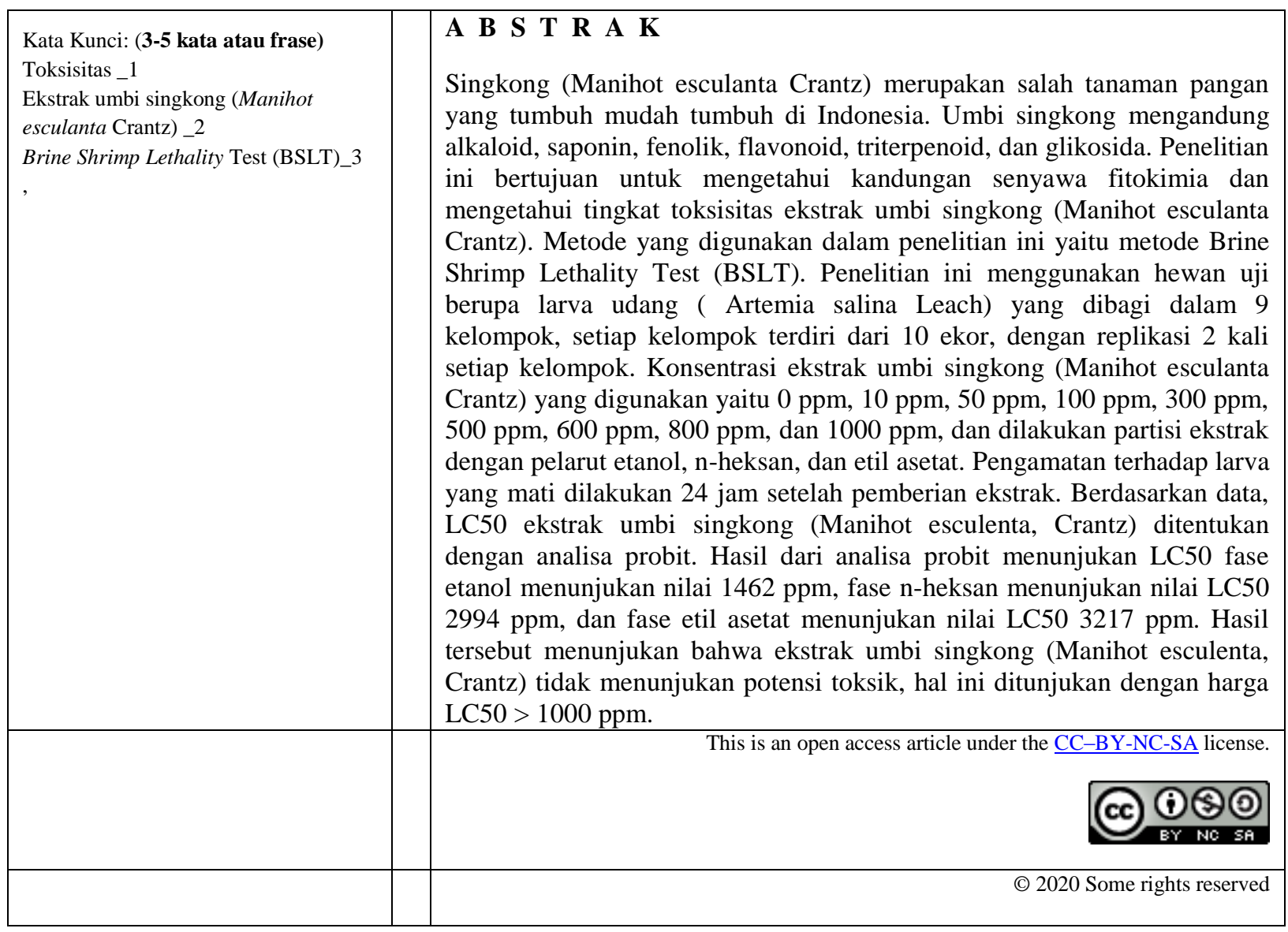


PENDAHULUAN

Penggunaan obat yang berasal dari tanaman saat ini menjadi pilihan bagi masyarakat. Menurut perkiraan badan kesehatan dunia (WHO),terdapat $80 \%$ penduduk dunia memilih melakukan pengobatan secara tradisional menggunakan bagian utuh tanaman untuk pertolongan pertama terhadap gangguan kesehatan. Sekitar 25\% dari obat yang beredar di dunia berasal dan dikembangkan dari tanaman yang kemudian bahan aktifnya yang diisolasi

Untuk spesies tanaman, ada setidaknya 1000 spesies yang telah diketahui manfaatnya sebagai bahan baku pembuatan obat Anonim, 1992). Telah ada penelitian yang menjelaskan bahwa tanaman tersebut menghasilkan metabolit sekunder sehingga dari setiap metabolit sekunder tersebut mempunyai kemampuan yang berbeda sehingga dapat dikembangkan sebagai obat sesuai dari struktur dan kemampuan biologinya sehingga memiliki potensi yang baik untuk dikembangkan menjadi obat Masyarakat indonesia sangat beragam, sebagian tersebar dan hidup sebagai suku di beberapa pelosok tanah air. Sebagian besar dari mereka masih memegang erat pengetahuan atau kearifan lokal suku mereka termasuk cara pandang dalam menghadapi dan mengobati penyakit, sehingga pada umumnya mereka memanfaatkan tumbuhan yang berada di sekitar lingkungan.

Senyawa toksik merupakan senyawa ataupun zat yang memiliki sifat racun dan dapat membahayakan apabila terakumulasi di dalam tubuh. Uji toksisitas adalah suatu uji yang dilakukan untuk mengetahui potensi adanya racun dari suatu sampel, mengetahui seberapa besar efek toksik tersebut melalui efek, karakteristik dan sifat biologi yang ditimbulkan (Priyanto, 2009).

Tanaman singkong biasanya dimanfaatkan masyarakat Indonesia untuk mengobati penyakit diantaranya demam, disentri, maag, anemia, typoid. Selama ini belum ada penelitian terhadap toksisitas ekstrak etanol umbi singkong yang diduga mempunyai efek toksik dan umbi singkong ini di harapkan dapat mengobati penyakit.

\section{METODE PENELITIAN}

Alat yang digunakan yaitu mortar dan stamper, kertas saring, pisau, cawan penguap, kaki tiga dan kassa asbes, pipet tetes, gelas ukur, gelas beker, tabung reaksi, penangas, rak tabung, batang pengaduk, water bath, timbangan analitik, allumunium foil, larutan spiritus, toples, kertas perkamen, corong kaca, oven dan airator. Bahan yang digunakan yaitu umbi 
singkong (Manihot esculenta Crantz), aquadestilata, kapas, air laut, telur udang aretmia salina leach, etanol $70 \%$, nHeksan, dan etil asetat.

Sampel yang digunakan adalah ekstrak umbi singkong yang telah dikelompokkan berdasarkan konsentrasi. Hewan uji yang digunakan adalah larva udang yang masih bergerak aktif (Artemia salina Leach) berumur 48 jam. Jumlah hewan uji yang digunakan pada penelitian ini sebanyak 180 ekor.

Masing-masing kelompok perlakuan menggunakan 10 ekor larva. Pada penilitan ini menggunakan 9 kelompok perlakuan, yaitu konsentrasi 0 ppm, 10 ppm, 50 ppm, 100 ppm, 300 ppm, 500 ppm, 600 ppm, 800 ppm, 1000 ppm. Dan masing-masing kelompok perlakukan dilakukan 2 kali pengulangan.

Penetasan larva Artemia salina Leach dilakukan selama 48 jam. Langkah yang dilakukan mempersiapkan alat penetas telur, alat tersebut dilengkapi dengan lampu sebagai sumber cahaya dan agar telur tidak mengendap maka ditambahkan aerator, aerator juga berfungsi sebagai penyuplai oksigen. Selanjutnya timbang telur Artemia salina sebanyak 5 gram per liter air laut. Telur Artemia salina di rendam dalam wadah berbentuk kerucut yang berisi air laut. Biarkan selama 24 jam. Selanjutnya telur yang telah menetas (larva) dipindahkan dalam wadah yang lebih kecil berisi $600 \mathrm{ml}$ air laut dan biarkan selama 48 jam.

Setelah usia larva 48 dari waktu penetasan, maka larva siap sebagai hewan uji. Selanjutnya dilakukan pembuatan larutan induk ekstrak umbi singkong dengan konsentrasi 2000 ppm atau sebanyak 400 mg ekstrak dalam $200 \mathrm{ml}$ air laut. Kemudian dilakukan pengenceran dengan air laut menjadi konsentrasi 0 ppm, 10 ppm, 50 ppm, 100 ppm, 300 ppm, 500 ppm, 600 ppm, 800 ppm, dan 1000 ppm.

Pembuatan partisi ekstrak n-Heksan dilakukan dengan menimbang $2 \mathrm{~g}$ ekstrak etanol umbi singkong lalu ditambahkan air sebanyak $20 \mathrm{ml}$, setelah larut dimasukkan dalam corong pisah dan ditambahkan dengan total n-Heksan sebanyak $65 \mathrm{ml}$, kemudian diuapkan didapatkan ekstrak kental. Cara tersebut juga dilakukan pada pembuatan partisi ekstrak etil asetat. 0 ppm, 10 ppm, 50 ppm, 100 ppm, 300 ppm, 500 ppm, 600 ppm, 800 ppm, dan 1000 ppm.

10 ekor larva Artemia salina Leach dimasukkan kedalam tabung reaksi yang berisi $10 \mathrm{ml}$ konsentrasi masing-masing kelompok perlakuan (10 ml untuk konsentrasi $10 \mathrm{ppm}, 10 \mathrm{ml}$ konsentrasi 50 $\mathrm{ml}, 10 \mathrm{ml}$ konsentrasi $100 \mathrm{ppm}, 10 \mathrm{ml}$ 
konsentrasi 300 ppm , 10 ml konsentrasi 500 ppm, $10 \mathrm{ml}$ konsentrasi 600 ppm, 10 $\mathrm{ml}$ konsentrasi $800 \mathrm{ppm}$ dan $10 \mathrm{ml}$ konsentrasi $1000 \mathrm{ppm}$. Selain itu, dibuat kontrol negatif yang berisi $10 \mathrm{ml}$ air laut tanpa penambahan ekstrak. Kriteria standar untuk menilai kematian larva udang adalah apabila larva udang tidak menunjukkan pergerakan selama beberapa detik observasi.

Data yang diperoleh merupakan data primer penelitian berdasarkan jumlah kematian larva udang setelah 24 jam perlakuan pada masing-masing kelompok perlakuan. Adapun pengamatan dilakukan dengan cara menghitung persentase kematian (mortalitas) larva Artemia salina Leach pada masing-masing kelompok perlakuan. Hasil perhitungan kematian diperoleh dari hasil perkalian rasio dengan $100 \%$ untuk tiap konsentrasi. Setelah itu, membandingkan pelarut ekstrak umbi singkong anatara polar, semipolar, dan nonpolar. Maka dapat diketahui ekstrak umbi singkong dengan pelarut manakah yang lebih toksik.

\section{HASIL}

Tabel 1. Hasil Partisi Ekstrak

\begin{tabular}{cccc}
\hline \multirow{2}{*}{ Parameter } & $\begin{array}{c}\text { Ekstrak } \\
\text { Etanol }\end{array}$ & P-Heksan & Etil Asetat \\
\hline Jumlah & 23 gram & 0,23 gram & 0,11 gram \\
Rendemen & $3,83 \%$ & - & - \\
Kadar Air & $62 \%$ & - & - \\
Kadar Abu & $10,92 \%$ & - & - \\
Kadar Abu tak larut asam & $0,04 \%$ & - & \\
Organoleptis & & & Coklat muda \\
a. Warna & Coklat muda & Coklat muda & Khas (aromatik) \\
b. Aroma & Khas (aromatik) & Khas (aromatik) & Pasta \\
c. Bentuk & Pasta & Pasta & Pahit \\
d. Rasa & Pahit & Pahit & \\
\hline
\end{tabular}


Berdasarkan Tabel 1, diketahui bahwa jumlah ekstrak etanol yang didapatkan adalah 23 gram, 0,4 gram. Hasil partisi ekstrak n-Heksan didapatkan sebanyak 0,24 gram, dan hasil partisi ekstrak etil asetat didapatkan sebanyak 0,11 gram. Hasil organoleptis yang didapatkan dari ketiga partisi ekstrak yaitu berwarna coklat muda, berbau khas aromatik, berbentuk pasta, dan memiliki rasa pahit.

Tabel 2. Hasil Uji Toksisitas Awal

\begin{tabular}{cc}
\hline Crude Ekstrak & Nilai LC $_{\mathbf{5 0}}$ \\
\hline Fase Etanol & $1462 \mathrm{ppm}$ \\
Fase n-Heksan & $2994 \mathrm{ppm}$ \\
Fase Etil Asetat & $3217 \mathrm{ppm}$ \\
\hline
\end{tabular}

Berdasarkan Tabel 2, diketahui bahwa ekstrak yang memiliki nilai toksisitas paling tinggi yaitu pada fase etanol dengan nilai LC $_{50}$ sebesar 1262 ppm , selanjutnya pada fase non polar (n-heksan) dengan nilai konsentrasi kematian $\left(\mathrm{LC}_{50}\right)$ sebesar 2994 ppm, dan pada fase semipolar (etil asetat) memiliki nilai konsentrasi kematian $\left(\mathrm{LC}_{50}\right)$ terendah yaitu 3217 ppm.

Tabel 3. Hasil Uji Fitokimia

\begin{tabular}{cc}
\hline Uji Fitokimia & Hasil \\
\hline Alkaloid & + \\
Saponin & + \\
Tanin & -
\end{tabular}

\begin{tabular}{cc} 
Fenolik & + \\
Flavonoid & + \\
Triterpenoid & + \\
Steroid & - \\
Glikosida & + \\
\hline
\end{tabular}

Berdasarkan Tabel 3, diketahui bahwa ekstrak umbi singkong (Manihot esculenta Crantz) memiliki kandungan alkaloid, saponin, fenolik, flavonoid, triterpenoid, glikosida.

\section{PEMBAHASAN}

Pada penelitian ini, untuk memastikan kebenaran suatu tanaman yang akan diteliti, agar terhindar terjadinya kesalahan dalam penentuan nama spesies tanaman, maka dilakukan determinasi terhadap bagian dari tubuh tanaman tersebut. Dari hasil determinasi tumbuhan tersebut diperoleh hasil bahwa tanaman yang akan diteliti adalah umbi dari tanaman jenis Manihot esculenta Crantz, suku Euphorbiaceae, dikenal sebagai Singkong.

Pengujian pada ekstrak umbi Manihot esculenta Crantz bertujuan untuk mengetahui toksik tidaknya umbi Manihot esculenta Crantz. Ekstrak etanol dengan berat 23 gram yang memiliki bentuk pasta berwarna coklat tua pekat beraroma khas aromatik kemudian dilarutkan ke dalam pelarut organik non organik hingga polar dilarutkan berurutan. Adapun penggunaan 
Etanol sebagai pelarut dikarenan etanol mempunyai tingkat kelarutan yang tinggi sehingga dapat melarutkan bahan aktif yang bersifat polar lebih banyak dibandingkan jenis pelarut polar lainnya, titik didih etanol yang rendah dan mudah menguap serta etanol tidak berbahaya dan beracun sehingga lebih aman untuk diaplikasikan untuk produk-produk farmasi, (Gamse T, 2002). Agar kandungan yang berada di ekstrak tersebut tidak rusak, maka tiap ekstrak yang telah diperoleh kemudian di pekatkan dengan water bath dengan suhu $70^{\circ} \mathrm{C}$.

Ekstrak etanol umbi Manihot esculenta Crantz yang sudah kental setelah melakukan tahap evaporasi, selanjutnya dipartisi dengan pelarut organik nonpolar hingga polar secara berurutan. Partisi ini bertujuan untuk memisahkan senyawa-senyawa yang bersifat nonpolar dan polar. Bagian yang larut tiap ekstrak yang didapat kemudian dipekatkan menggunakan waterbath dengan suhu 40 sampai $50^{\circ} \mathrm{C}$ hingga kering.

Partisi awal menggunakan pelarut nHeksan yang bersifat non-polar dengan perbandingan ekstrak etanol kental : nHeksan (4 gram/20 ml : $65 \mathrm{ml}$ ) sebanyak 3 kali partisi, maka akan diperoleh fase
n-Heksan seberat 0,23 gram. Alasan penggunaan $n$-Heksan sebagai pelarut karena n-Heksan bersifat nonpolar, sehingga dapat menarik senyawa polar dan non polar.

Tahap berikutnya partisi dengan pelarut Etil asetat yang bersifat semipolar dengan total penambahan $65 \mathrm{ml}$ dan diperoleh fase Etil asetat seberat 0,11 gram. Penggunaan Etil asetat sebagai pelarut karena Etil asetat bersifat semipolar, sehingga dapat mengikat senyawa aktif yang larut air (polar) dan tidak larut air (non polar), memiliki toksisitas rendah, dan mudah diuapkan.

Dari hasil penelitian uji toksisitas yang dilakukan menunjukan bahwa fraksi larut air yang menggunakan pelarut etanol diperoleh bahwa kematian larva $\left(\mathrm{LC}_{50}\right)$ berada pada konsentrasi 1462 ppm. Senyawa polar yang terkandung dalam umbi singkong diantaranya flavonoid, fenolik, glikosida, dan saponin karena senyawa tersebut larut pada pelarut organik polar seperti etanol.

Pada pengujian menggunakan pelarut yang menggunakan pelarut semipolar diperoleh bahwa kematian larva $\left(\mathrm{LC}_{50}\right)$ berada pada konsentrasi 3217 ppm. Senyawa semipolar yang terkandung dalam umbi singkong diantaranya 
flavonoid, steroid, alkaloid karena senyawa tersebut larut pada pelarut organik semipolar seperti Etil asetat.

Pada pengujian menggunakan pelarut nHeksan yang menggunakan pelarut nonpolar diperoleh bahwa kematian larva ( $\mathrm{LC}_{50}$ ) berada pada konsentrasi 2994 ppm. Senyawa nonpolar yang terkandung dalam umbi singkong diantaranya steroid, alkaloid, triterpenoid karena senyawa tersebut larut pada pelarut organik nonpolar seperti n-Heksan.

Hasil uji toksisitas crude ekstrak umbi singkong (Manihot esculenta Crantz) dengan metode BLST menunjukan bahwa ekstrak Manihot esculenta Crantz dari ketiga fase tersebut yaitu fase etanol dengan nilai LC $_{50}$ pada konsentrasi 1462 ppm, fase Etil asetat dengan nilai $\mathrm{LC}_{50}$ pada konsentrasi 3217 ppm, dan fase nHeksan dengan nilai $\mathrm{LC}_{50}$ pada konsentrasi 2994 ppm. Hasil tersebut tidak menunjukan efek toksisitas pada larva Artemia salina karena senyawa dapat dikatakan toksik apabila memiliki nilai memiliki nilai $\mathrm{LC}_{50}$ kurang dari 1000 ppm (Wagner et al., 1993).

Pada uji fitokimia menunjukan bahwa pada umbi singkong (Manihot esculenta Crantz) terdapat adanya senyawa metabolit sekunder yaitu alkaloid, saponin, fenolik, flavonoid, triterpenoid, glikosida. Senyawa alkaloid memiliki kemampuan sebagai penstimulasi sistem syaraf, menaikan tekanan darah, mengurangi rasa sakit, antibakteri dan anti jamur, obat penenang (Robinson, 1995).

Senyawa saponin mempunyai efek terhadap sistem imun spesifik, diantaranya adanya potensi sebagai senyawa sitotoksik terhadap sel kanker, antitumor, antiinflamasi, dan antimutagen (Wagner, 1996). Saponin bersifat toksik bagi hewan berdarah dingin sehingga banyak diantaranya digunakan sebagai racun ikan (Gunawan dan Mulyani 2010).

Senyawa fenolik memiliki kemampuan sebagai antioksidan, antiradical bebas, antialergi, anti radang, dan antiradiasi sinar UV (Berthon et.al,, 2017). Adapun manfaat lainnya, diantaranya sebagai penghambat pelepasan histamin ketika terjadi elergi yang menyebabkan peradangan pada kulit, sehingga mampu mencegah terjadinya dermatitis atopic (Heo et al., 2009).

Senyawa flavonoid memiliki kemampuan sebagai agent antioksidan, antimikroba, antivirus, antiinflamsi, antialergi, dan anti kanker (Miller 1996). Menurut Robinson 1995 senyawa ini dapat digunakan sebagai antihipertensi, merangsang pembentukan 
estrogen, dan mengobati gangguan fungsi hati.

Senyawa triterpenoid memiliki fungsi sebagai pertahanan terhadap serangga senyawa pengganggu dan senyawa ini merupakan komponen aktif dalam tumbuhan obat yang telah digunakan untuk penyakit diabetes, gangguan menstruasi serta beberapa senyawa triterpenoid menunjukan aktifitas antibakteri atau antivirus (Harborne 1987; Robinson 1995). Glikosida memiliki potensi terapeutik yang sering digunakan sebagai obat jantung yaitu glikosida dari digitalis, atrophanthus, squill, convallaria, apocynum. Adapun glikosida antrakinon dalam bentuk "morindon" dapat digunakan sebagai obat pencahar (Ningsih IA et al., 2003).

\section{KESIMPULAN}

Hasil Penelitian menunjukan bahwa nilai $\mathrm{LC}_{50}$ fraksi Etanol umbi singkong berada pada konsentrasi 1462 ppm, nilai LC $_{50}$ fraksi Etil asetat umbi singkong berada pada konsentrasi 3217 ppm, dan nilai LC $_{50}$ fraksi n-Heksan umbi singkong berada pada konsentrasi 2994 ppm.

Organoleptis ekstrak umbi singkong didapatkan hasil warna coklat tua, berbentuk pasta, berasa pahit, dan berbau khas (aromatik).
Hasil uji fitokimia diketahui bahwa alkaloid, saponin, fenolik, flavonoid, triterpenoid, glikosida merupakan senyawa yang paling aktif yang terkandung dalam umbi singkong.

\section{DAFTAR PUSTAKA}

Anonim, 1992. (diambil dari Jenova R, 2009). Uji Toksisitas Akut Yang Diukur Dengan Penentuan LD50 Ekstrak Herba Putri Malu (Mimosa pudica L.) Terhadap Mencit. [Skripsi]. Universitas Diponegoro : Semarang.

Berthon JR, Nachat KM, Bey JP, Renimel dan Filarire E. 2017. Marine Algae as Attractive Source to Skin Care. Free Radical Research

Dalimarta, 2000. (diambil dari Jenova R, 2009). Uji Toksisitas Akut Yang Diukur Dengan Penentuan LD50 Ekstrak Herba Putri Malu (Mimosa pudica L.) Terhadap Mencit. [Skripsi]. Universitas Diponegoro : Semarang.

Gamse T. (2002). Liquid-Liquid Extraction and Solid Liquid Extrsction. Institute of Thermal Process and Environmental Engineering.

Gunawan D, dan Mulyani S. (2010). Ilmu Obat Alam (Farmakognosi) Jilid 1. Penebar Swadaya : Jakarta.

Harbone JB (1987). Metode Fitokimia: Penuntun Cara Modern Menganalisis Tumbuhan, Terbitan Kedua. ITB : Bandung.

Heo SJ, Ko SC, Cha SH, Kang DH, Park HS dan Choi Y. (2009). (diambil dari Sedjati S, Suryono, Santosa A, Ssupriyantini dan Ridlo A. 2017). Aktivitas Antioksidan dan Kandungan Senyawa Fenolik Makroalga Coklat. Jurnal. Fakultas Perikanan dan Ilmu 
Kelautan. Universitas Diponegoro : Semarang.

Marlina N. (1996). Analisis Sianida dalam singkong dengan Metode Lian dan Hamir yang Dimodifikasi. Balai Penelitian Ternak : Bogor.

Miller AL. (1996). Antioksidan Flavonoid : Struktur, Fungsi, dan Penggunaan Klinis. Jurnal Tinjauan Obat Alternatif. Volume 1. Thorne Research, Inc.

Ningsih IA, Chatun S, dan Anggarwulan E. (2003). Pertumbuhan Kalus dan Produksi Antrakuinon Mengkudu (Morinda citrifolia L.). Jurnal. Jurusan Biologi FMIPA. UNS : Surakarta.

Priyanto. (2009). Toksikologi : Mekanisme, Terapi Antidotum, dan Penilaian Resiko. Leskonfi : Depok.

Rahayu MS. (2011). Pemanfaatan Tumbuhan Obat Oleh Masyarakat Kabupaten Subang, Jawa Barat. [Skripsi]. Institut Pertanian Bogor : Bogor.

Robinson T. (1995). Kandungan Organik Tumbuhan Obat Tinggi. Diterjemahkan oleh Kokasih Padmawinata. ITB : Bandung.

Wagner $\mathrm{H}$ dan Bladt S. (1993). Pharmazeutische Biologie. New York : USA.

Wagner H. (1996). Plant Drug Analysis : A Thim Layer Cromatography Atlas. Edisi II. Springer : New York. 